УДК 821.161.2Д-3.09-055.2

DOI https://doi.org/10.26661/2413-6549-2020-2-05

\title{
АВТОМАТИЧНА ГЕНЕРАЦІЯ НАВЧАЛЬНИХ ТЕСТІВ ЗА ДОПОМОГОЮ ПРОГРАМНОЇ ОБРОБКИ ПРИРОДНО-МОВНИХ ТЕКСТІВ
}

\author{
Ковальов Д. І. \\ аспірант \\ Київський начіональний університет імені Тараса Шевченка \\ пр. Глушкова, 4Д, Київ, Україна \\ orcid.org/0000-0002-6014-4474 \\ daniil.kovaliov@gmail.com
}

\author{
Ключові слова: формальна \\ семантика, семантичний \\ аналіз, обробка мови, \\ генерація навчальних тестів, \\ лінгвістичний прочесор.
}

У статті розглядаються основні технології, які сьогодні використовуються в електронному навчанні в багатьох вищих навчальних закладах. Згадано пакет програм SMPR, створений студентами факультету кібернетики та інформаційних технологій Київського національного університету імені Тараса Шевченка протягом декількох років. Їх метою є спрощення процесу навчання, консультування та перевірки знань учнів як для викладачів, так і для студентів. SMPR використовується для навчання викладачами кількох університетів для підтримки курсу «Теорія рішень» та інших предметів прикладних наук. У 2014 році цей програмний пакет удосконалено за допомогою автоматизованої підсистеми оцінки знань, що є основною темою статті. У межах автоматизованого оцінювання $€$ проблема оцінювання відкритих текстових відповідей. Викладачі хотіли б знати якість знань учнів, ставлячи відповідні запитання, що вимагають опису процесів мислення. Однак немає жодних автоматизованих рішень, які могли хоча б попередньо оцінити такі відповіді. Рішення, певно, лежить у галузі NLP та видобутку даних. Після деяких досліджень iз цих тем автор натрапив на статті, що описують підходи до аналізу даних та тексту, а основа для цих рішень лежить у базах знань. Також у тексті виокремлюються фрагменти інтенсивної логіки 3 точки зору впровадження технічної системи, яка спрямована на роботу з природними текстовими даними. Розглянуто принципи застосування інтенсивної логіки Р. Монтегю для формалізації текстових даних, представлених природною мовою, з метою створення баз даних знань, необхідних для подальшої реалізації автоматичної генерації навчальних тестів. Далі пропонується практичний підхід до завдання генерації навчальних тестів, заснований на технології вилучення знань із природно-мовних текстів із використанням програмного лінгвістичного процесора. 


\title{
AUTOMATIC GENERATION OF EDUCATIONAL TESTS WITH THE HELP OF SOFTWARE PROCESSING OF NATURAL LANGUAGE TEXTS
}

\author{
Kovaliov D. I. \\ Postgraduate Student \\ Taras Shevchenko National University of Kyiv \\ Glushkova str., 4D, Kyiv, Ukraine \\ orcid.org/0000-0002-6014-4474 \\ daniil.kovaliov@gmail.com
}

Key words: formal semantics, semantic analysis, language processing, generation of educational tests, linguistic processor.

\begin{abstract}
The article reviews the main technologies used today in e-learning across multiple institutions of higher education. Also mentioned the SMPR software package created by students of the faculty of Cybernetics and Information Technology in Taras Shevchenko National University of Kyiv over several years. The purpose of the program is to simplify the process of education, consultation and testing students' knowledge for both - teachers and students. SMPR used for education by teachers of several universities to support the course "Decision Theory" and other subjects of applied science. In 2014, this software package have been improved with automated knowledge evaluation sub system, which is the main topic of the article. As part of automated evaluation, the problem of evaluating open text answers raised. Teachers would like to know the quality of student knowledge by providing appropriate questions that require thought processes to be described. Meanwhile there's no any automated solutions that can at least make a pre-evaluation of such answers. Solution seems to be lying in a field of NLP and data mining. After some basic research in those topics author came across articles that describes approaches to data mining and text analysis, and the base for this solutions lies in databases of knowledge. The article separates fragments of intensive logic in terms of implementing a technical system that aims to work with natural text data. The principles of application of intensive logic of Richard Montague for formalization of the textual data presented in natural language for the purpose of creation of databases of knowledge necessary for the further realization of automatic generation of educational tests are considered. Next, a practical approach to the problem of generating educational tests, based on the technology of extracting knowledge from natural language texts using a software linguistic processor.
\end{abstract}

Вступ. Відомо, що освітні технології (згідно 3 визначенням Асоціації освітніх комунікацій та технологій) - це «дослідження й етичні практики сприянню навчальному процесу та підвищенню його продуктивності шляхом створення, використання й управління відповідних технологічних процесів і ресурсів» [1].

Освітні технології належать як до фізичних компонентів, так і до освітніх теорій.

Вони включають кілька доменів, серед яких $\epsilon$ теорія навчання, комп'ютерне навчання, навчання в онлайн-режимі, а також мобільне навчання (з використанням мобільних технологій). Відповідно, є декілька дискретних аспектів опису інтелектуального і технічного розвитку освітніх технологій:

- в теорії і практиці освітніх підходів до навчання;

- як технічні засоби і засоби масової інформації, які допомагають у переданні знань, а також у їх розвитку й обміні;
- для систем управління навчанням (далі - LMS), такі як інструменти для студентів або системи управління навчальними програмами, а також інформаційні системи управління освітою;

- як тематика навчального предмета; такі курси можуть бути названі «Комп’ютерні дослідження» або «Інформаційні та комунікаційні технології».

Стрімкий розвиток інформаційних технологій останніми десятиріччями ставить перед суспільством низку завдань ефективної обробки великих масивів слабко структурованої інформації, представленої у вигляді програмних ресурсів та вебсторінок. Серед них виділяють створення стандартів розроблення програмних ресурсів визначених типів, пошук, видобування, оброблення, аналіз, збереження та відображення інформації.

Експоненціальне зростання кількості інформаційних джерел зумовлює розвиток таких напрямів, як інтелектуальний аналіз даних (Data mining), 
видобування даних із вебсторінок (Web mining), методи інтелектуального пошуку інформації, машинне навчання, кластерний та регресійний аналіз.

Пошук та аналіз текстової інформації досліджували видатні вітчизняні та зарубіжні вчені (А.В. Анісімов, Т.В. Виноград, І.Р. Гальперін, А.М. Глибовець, М.М. Глибовець, А.Ж. Греймас, I.М. Кобозева, М.А. Кронгауз, Дж. Лакофф, Д.В. Ланде, Н.Н. Леонтьєв, Д.Ф. Люгер, Д. Маккарті, О.О. Марченко, І.А. Мельчук, А. Ньюелл, С. Осуга, У. Піттс, Е.В. Попов, Д.А. Поспєлов, В.Ш. Рубашкін, І.П. Севбо, Д.М. Фостер, Дж. Хопкрофт, Ю.І. Шемакін, В.А. Широков). Відкритими залишаються питання створення методів автоматичного видобування інформації 3 програмних та текстових ресурсів.

У цій статті ми більш детально розглянемо LMS-систему SMPR.

Система SMPR - додаток до курсу «Теорія прийняття рішень». У 2006 році командою студентів факультету кібернетики Київського національного університету імені Тараса Шевченка започатковано проект під назвою «SMPR (системи та методи прийняття рішень)». Його основна мета - надання методичних даних із предмета «Теорія прийняття рішень» студентам, проведення тестування за деякими з модулів предмета та виконання завдань із предмета.

На початку 2014 року ухвалено рішення «розширити» проект. Він дозволив створювати та проводити тестування з будь-якого предмета. За основу взято платформу ASP.NET C\# [5], а саме MVC Framework.

Причиною такого вибору стала необхідність задовольнити потребу максимальної доступності програмного забезпечення та його незалежність від платформи. Вищезазначені технології володіють указаними властивостями та дозволяють створити вебсайт, що має простий та зрозумілий зовнішній вигляд і складні алгоритми та обчислення на сервері.

Вебсайт дозволяє викладачам створювати серії питань різного типу, об'єднані до тестів.

Оцінку за кожне питання буде окреслено алгоритмами, що згадувалися вище, після того, як група студентів, визначена викладачем, завершить проходження тесту. Це сесія в термінах програми. Викладач може власноруч виставляти початкову оцінку 3 кожного питання або дочекатись результатів першої сесії, щоб почав працювати алгоритм вибору наступного питання відповідно до середньої оцінки студента та його відповіді на попереднє запитання.

Протягом 2014-2016 навчальних років вебсайт уведено в тестову експлуатацію за участю студентів 3 курсу факультету кібернетики. Тоді в тестуванні взяли участь близько 90 студентів. Як наслідок, значно скоротився час перевірки знань, що допомогло викладачам визначити обсяг знань кожного студента за темами. Про результати використання системи в навчальному процесі Київського національного університету імені Тараса Шевченка доповідано на міжнародній конференції [4].

Для подальшого ефективного розроблення розглянутої системи постало завдання впровадження методів формалізації створення вихідної бази навчальних знань та автоматичної генерації навчальних тестів із використанням технологій розпізнання природно-мовних текстів.

Використання логіки Монтегю для створення баз знань. Ефективне використання знань у текстах вимагає нових стратегій оброблення інформації, що відрізняються від традиційних підходів. Вони повинні враховувати семантичні закони природної мови.

Вивчення семантики речення тісно пов'язане 3 мисленням. Зважаючи на актуалізацію проблеми автоматизації оброблення природно-мовних текстів за допомогою комп'ютера, з'явилися спроби формалізації методів роботи з семантикою в межах логіки.

Проста паралелізація одного завдання. Символьні формули досить просто розділяються на підформули. Виводимість окремої підформули найчастіше можна перевіряти окремо від інших. Ця властивість особливо важлива, зокрема, 3 огляду на тенденцію широкого поширення розподіленого оброблення даних.

Множинність виконуваних завдань на єдиному наборі знань. Логічне уявлення дозволяє на єдиному наборі даних/знань виробляти різні операції.

Природне пояснення результатів операцій. Логіка формалізує правила мислення, тому результати набору логічних операцій (за достатньої дружності призначеного для користувача інтерфейсу) можуть легко розумітися користувачем. У логічній пошуковій системі можна показати ланцюжок умовиводів, на основі яких пропонований текст зараховано до релевантних результатів пошуку. Більшість наявних методів не дають такої можливості пояснення результату, оскільки набори векторних і статистичних даних, із якими вони працюють, набагато складніше уявити в доступному для непідготовленого користувача вигляді. Так, на одній базі можуть функціонувати пошукові системи, питально-відповідні системи, системи розпізнавання образів тощо.

Розвиток логічного підходу до вивчення семантики можна простежити на основі наявних семантик некласичних логік: семантики сенсу і денотата Г. Фреге, теорії об’єктів і пропозицій Б. Рассела, теорії істини А. Тарського, семантики можливих світів С. Крипке, логіки сенсу і денотата А. Черча. Найбільш перспективним із точки зору засто- 
сування в автоматичному семантичному аналізі є підхід, запропонований Р. Монтегю. Він сформував цілий напрям, що отримав назву «формальна семантика» [9]. Основна ідея робіт Монтегю виражена в назві однієї з його основних праць «English as a formal language ». Будь-яку природну мову (зокрема, англійську) пропонується розуміти як формальну логічну мову, яка $є$ більш складною відповідно до наявних формальних мов. Отже, під час описування природної мови можна використовувати ті ж поняття і конструкції, що й для інших логічних мов [10].

Центральний принцип формальної семантики полягає в композиційному відношенні між синтаксисом i семантикою. Принцип композиціональності можна описати так: значення виразу функція його частин та способу їх синтаксичної комбінації. При цьому істинність визначається не абсолютно, а в межах певної моделі [10].

$€$ два підходи до вивчення семантико-синтаксичних зв'язків:

- опис синтаксису природної мови (тут - української) й інтерпретація мовних виразів у моделях;

- використання проміжної логічної мови, для чого необхідно описати синтаксис i семантику досить близького до природної логічної мови; при цьому опис семантики природної мови зводиться до подання тексту в сконструйованій логічній мові.

Для досягнення більшості практичних цілей другий підхід $є$ більш перспективним, оскільки дозволяє реалізувати вищеописані переваги логічного представлення мов.

У роботі [9] Монтегю використовує таку пару координат, як можливі світи і тимчасові проміжки, щодо яких для кожного виразу визначаються інтенсіонал й екстенсіонал. Моделлю для інтенсіональної логіки Монтегю є така п’ятірка виду: $\mathrm{M}=\mathrm{D}, \mathrm{W}, \mathrm{T} \leq$, I, де $\mathrm{D}-$ множина індивідів; W - множина можливих світів; T - множина моментів; $\leq-$ відношення порядку, задане на T; I - інтерпретувальна функція, яка надає семантичні значення всім константам.

Семантична інтерпретація інтенсіональної логіки використовує множину оцінок $\mathrm{S}=\left\{\mathrm{g}_{\mathrm{i}} \mid \mathrm{i}=1, \ldots \mathrm{n}\right\}$, які $є$ множиною функцій, що відображають змінні всіх типів у множині відповідних значень (g - функція приписування значення змінної); $\pm^{\mathrm{M}, \mathrm{g}} \quad$ інтенсіонал вираження щодо моделі М і функції приписування $\mathrm{g} ; \pm^{\mathrm{M}, \mathrm{w}, \mathrm{t}, \mathrm{g}}-$ екстенсіонал виразу $\alpha$ щодо $\mathrm{M}, \mathrm{g}$ i точки співвіднесення $\mathrm{w}, \mathrm{t}$, де $\mathrm{w} \in \mathrm{W}, \mathrm{t} \in \mathrm{T}$.
Із точки зору реалізації технічної системи можна виділити такі фрагменти обробки текстової інформації засобами формальної семантики (рис. 1) [9].

Схема наочно показує, як відбувається функціональний розподіл частин єдиної системи під назвою «логіка Монтегю». У блоці «мовний складник» об'єднано елементи, характерні для конкретної природної мови.

Формальне представлення не залежить від конкретної мови і $є$ єдиним для багатьох реалізацій мовних складників. Зараз основні дослідження зосереджені у сфері природно-мовного складника (із внесенням необхідних змін до постулату значення).

На мовний складник уводяться обмеження таким чином, щоб він представляв підмножину природної мови, мінімально необхідну для подання простих мовних фраз.

Сучасне вивчення формальної семантики зводиться саме до визначення способів переходу від природно-мовного уявлення до формалізованого логічного. Можуть бути різні способи таких переходів.

Для реалізації механізму заповнення бази знань пропонується розширити тлумачення терміна «інтерпретація», використовуваного у формальній семантиці. Під інтерпретацією тут розуміється не просто обчислення істинного значення формули, але й відображення знакового подання виразу на певну картину світу. При цьому може проводитися інтерпретація як із метою обчислення виразу, так і для зміни моделі предметної сфери, в якій проводиться відображення. Для заповнення бази знань на основі даних тексту будується формальне подання природно-мовного тексту у вигляді множини набору формул інтенсіональної логіки. Потім визначається цільова семантична мережа і здійснюється ії клонування, результатом якого є семантична мережа, що має позначки на всіх вузлах, які показують іiі належність до певного тексту. Далі відбувається інтерпретація кожної формули 3 метою нанесення ознак об'єктів, представлених у формулі, на семантичну мережу.

Принципи розроблення системи автоматичної генерації навчальних тестів. Із метою практичної апробації підходу пропонується розроблення окремого програмного модуля, що дозволяє фор-

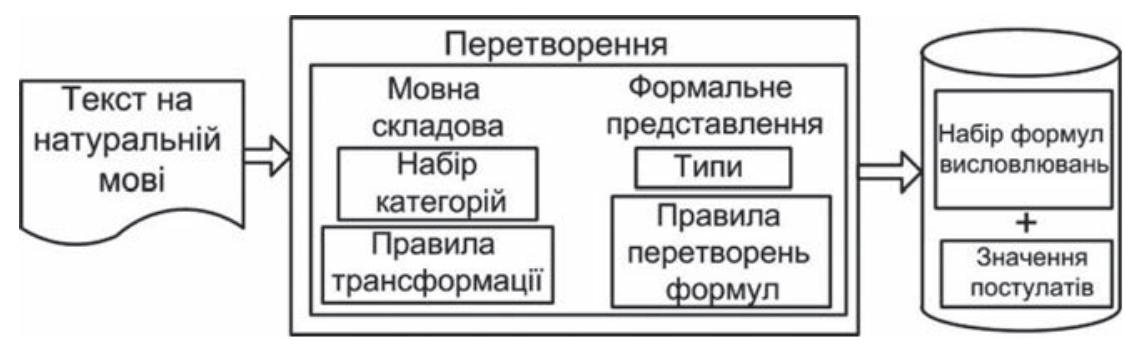

Рис. 1. Обробка текстової інформації у формальній семантиці на основі інтенсіональної логіки Монтегю 
мувати тестові завдання для подальшого їх передання до загальної системи тестування

Основна ідея запропонованого методу полягає у створенні системи, яка автоматично генерує тестові завдання до електронних навчальних посібників і представляє їх викладачеві, який може використовувати їх для завершення тесту і для оцінювання студентів.

Система зважає на текст інструкцій для вступу i форми випробування завдань на вихід. Потім згенеровані завдання тесту представлені викладачеві, який обирає та редагує завдання, якщо вони будуть корисними.

Основними засобами, що реалізують цей підхід, є лінгвістичні процесори, які одне за одним обробляють вхідний текст.

Вхід одного процесора є виходом іншого.

Процесори виконують аналіз тексту на різних рівнях мови:

- графематичному (виділення речень, слів, чисел, формул тощо);

- морфологічному (побудова морфологічної інтерпретації слів вхідного тексту);

- синтаксичному (побудова дерева залежностей речень);

- семантичному (побудова семантичного графу тексту).

Необхідною попередньою процедурою для подальшого аналізу тексту в будь-якій системі аналізу природних мов є виділення речень із суцільного тексту. У першому приближенні речення $€$ послідовністю символів, закінчується такими символами, як «.», «!» або «?», однак на практиці слід ураховувати можливість використання точки як символу скорочення та інші нюанси [9]. У запропонованому графематичному алгоритмі використовуються зумовлені набори загальноприйнятих («р», «рр.», «і т.д.») і поширених («тому що», «тобто», «т.зв.») скорочень, а також ураховується можливість скорочення ініціалів у власних іменах («Т.Г. Шевченко» тощо). Наслідком роботи алгоритму є масив речень (фраз), які в подальшому можуть оброблятися алгоритмами морфологічного й синтаксичного аналізів.

Для отримання тестових завдань різних видів у цьому підході застосовують різні види алгоритмів синтезу питань. Ці алгоритми відрізняються глибиною аналізу природної мови, їх можна розділити на дві групи.

Алгоритми першої групи здійснюють заміну шуканого слова в реченні на комбінацію символів «?» (за кожним реченням вихідного тексту може бути побудовано не більше одного питання).

До цієї групи належать такі алгоритми: пошук скорочень (абревіатур), пошук чисельних значень, генерація на основі визначень, генерація 3 конструкцій «якщо ..., то ...».
Алгоритми цієї групи грунтуються на тривіальному перегляді фрази й пошуку необхідних символів (або ж конкретних слів). Ці алгоритми реалізуються на практиці і відрізняються порівняно високою швидкодією, однак часто показують неприйнятні результати.

Алгоритми другої групи виконують побудову питання за результатами синтаксичного аналізу тексту. Сюди належать такі: питання до підмета (що?, хто?, ...), питання до прикметника (який?, яка?, ...), питання до обставини місця (де?), питання до обставини часу (коли?). Ці алгоритми вимагають наявності розвинутого морфологічного словника. Для запропонованого програмного продукту вони можуть бути реалізовані за допомогою синтаксичних бібліотек вебресурсів типу ru.glosbe.com/ru/uk.

Для прикладу опишемо алгоритм формування питання до прикметника. Блок-схему цього алгоритму представлено на рис. 2. На початку роботи ініціалізуються змінні А, В, С: А - обробляється речення 3 масиву тексту; В - відповідь на запитання (присвоюється порожній рядок); 3 - готове речення для тестування (за замовчуванням дорівнює А). Потім за допомогою методу FindSituation() синтаксичних бібліотек здійснюється синтаксичний аналіз речення А. Далі ініціалізуються допоміжні змінні для роботи алгоритму: flag = істина (сигналізатор знайденої фрази для генерації питання), $\mathrm{j}=0$ (змінна циклу, номер поточного вузла речення). До змінної К записується кількість вузлів у вже згадуваному реченні. Потім починається цикл із передумовою: поки ј менше або одне (K-1) i flag = істина. У циклі послідовно аналізується кожен синтаксичний вузол речення. Якщо у вузлі визначається тип відносин «властивість», то за допомогою методу GetGramInfo () описуються граматичні характеристики залежного слова. Якщо це слово є прикметником, то воно записується до змінної В. Нарешті, формується питання з урахуванням форми прикметника (його характеристик, одержуваних від зазначеного вище методу). Для закриття циклу змінної flag присвоюється значення неправди.

Якщо текст обробляється тільки до рівня синтаксису без урахування семантики, то не всі генеровані питання можуть бути доречними в цій предметній сфері. Зважаючи на це, на користувача може лягти досить складне завдання вибору питань. Проте випробування підходу на конкретних навчальних дисциплінах показали, що навіть за такої реалізації підхід дає порівняно непогані результати. Наприклад, щодо навчального посібника 3 дисципліни «Моделі та методи прийняття рішень» (авт. О.Ф. Волошин та С.О. Мащенко), то за допомогою алгоритмів другої групи вдалося отримати 42\% завдань, придатних для використання в тесті без зміни, і 24\% завдань, із яких можна 
отримати придатні завдання шляхом редагування (тобто більше половини отриманих завдань виявилися придатними для складання тестів за меншого чи більшого ступеня участі викладача). Алгоритми першої групи демонстрували користь під час аналізу посібників, що містять велику кількість чисел, але в інших випадках часто виявлялися малоефективними (близько 15\% придатних завдань).

Висновки. Розглянутий метод із використанням логіки Монтегю має практичні перспективи щодо полегшення роботи викладача під час складання тестів. На його основі можуть бути побудовані програмні засоби для автоматичної генерації навчальних тестів. Цей метод можна легко доповнити нейроме- режевими технологіями для підвищення різноманітності та складності створюваного навчального матеріалу. У методі виділяють такі етапи:

1) формалізацію природно-мовної фрази;

2) інтерпретацію формули формальної семантики;

3) заповнення бази знань.

Новизна роботи полягає в розробленні та використанні лінгвістичних процесорів, які одне за одним обробляють вхідний текст 3 урахуванням особливостей понять теорії ухвалення рішень. Це відбувається за рахунок створеної семантичної мережі, що має позначки на всіх вузлах, що показують іï належність до певного тексту.

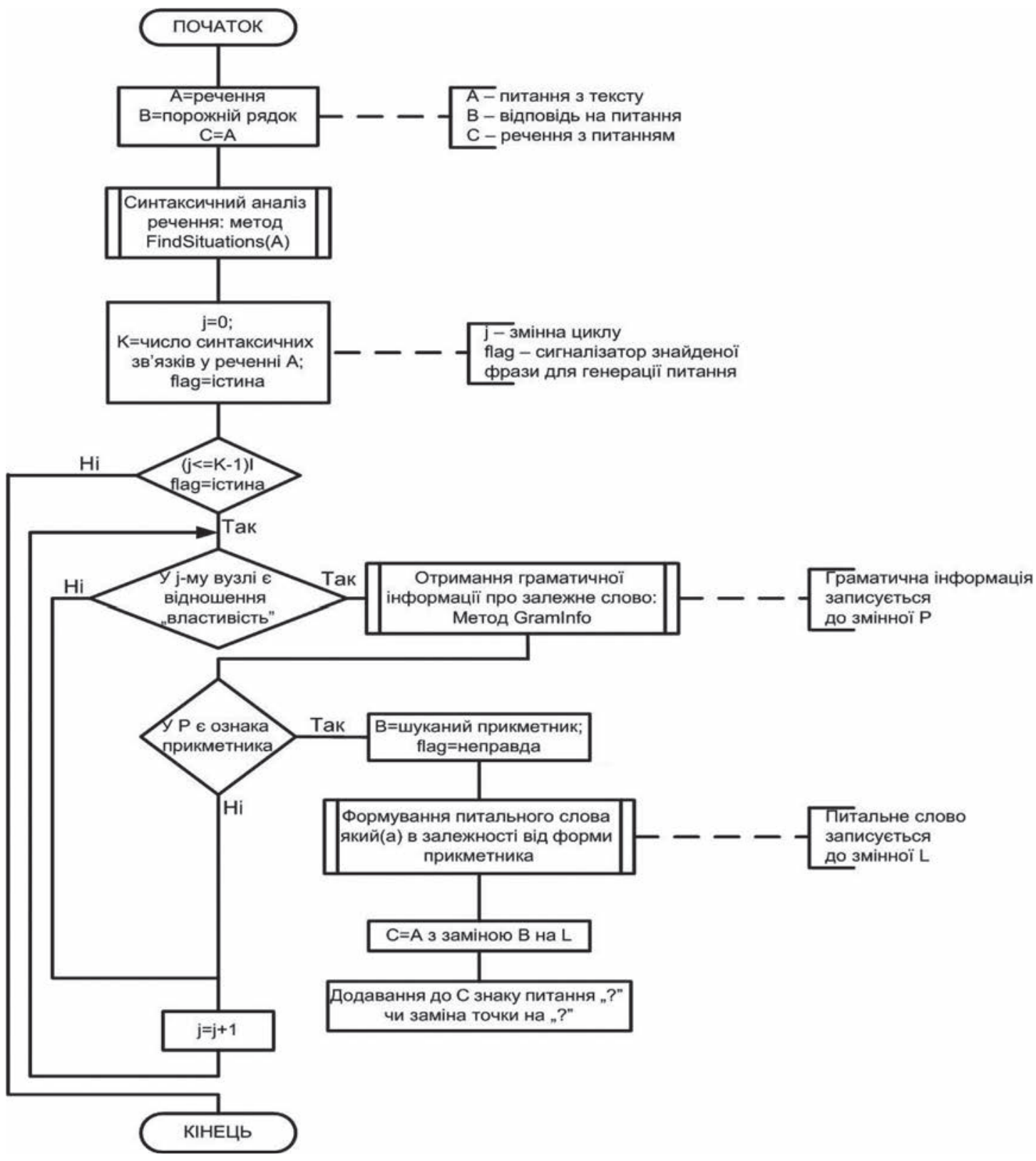

Рис. 2. Блок-схема алгоритму генерації питань до прикметником 


\section{ЛITЕРАТУРА}

1. Robinson, Rhonda; Molenda, Michael; Rezabek, Landra. "Facilitating Learning" (PDF). Association for Educational Communications and Technology. Retrieved 18 March 2016.

2. Courts, B., \& Tucker, J. Using Technology To Create A Dynamic Classroom Experience. Journal of College Teaching \& Learning (TLC), 9(2), 2012, pp. 121-128.

3. Снитюк В.Е., Юрченко К.М. Интеллектуальное управление оцениванием знаний, Маклаут, Черкассы 2013. 224 c.

4. O.F. Voloshyn, D.I. Kovaliov "Educational system support to decision making theory", Computer Science And Information, Technologies Conference, Yerevan 2013, P. 433-434.

5. A. Freeman, M. MacDonald, M. Szpuszta, "Pro ASP.NET 4.5 in C\#" [5th Edition] Apress, 2013.

6. H. Kniberg "Scrum and XP from the Trenches (Enterprise Software Development)", www.lulu.com 2007.

7. Волошин О.Ф., Кудін В.І. Використання новітніх навчальних технологій у Київському національному університеті імені Тараса Шевченка. Класичний університет у контексті викликів епохи (Classic University in the Context of Challenges of the Epoch) : матеріали українсько-польської міжнародної наукової конференції (м. Київ, 22-23 вересня 2016 року) / уклад.: А.С. Філіпенко та ін. Київ : Київський національний університет імені Тараса Шевченка, 2016. С. 167.

8. Ковальов Д.І. Сервіс Дистанційного навчання у форматі соціальної мережі. Вісник КНУ. Серія фізико-математичні науки. 2015.

9. Montague, R. English as a formal language / edited by R. H. Thomason. Formal Philosophy. Yale University Press, 1974.

10. Швецов А.Н., Алешин В.С. Построение приближенной концептуальной модели предметной области на основе анализа смысла естественно-языковых текстов. Международная конференция по мягким вычислениям и измерениям SCM’2003 : сб. докл. Т. 2. Санкт-Петербург, 2003. С. 120-123.

\section{REFERENCES}

1. Robinson, Rhonda; Molenda, Michael; Rezabek, Landra. "Facilitating Learning" (PDF). Association for Educational Communications and Technology. Retrieved 18 March 2016.

2. Courts, B., \& Tucker, J. Using Technology To Create A Dynamic Classroom Experience. Journal of College Teaching \& Learning (TLC), 9(2), 2012, pp121-128.

3. Snítyuk V. Ye., Yurchenko K. M. Intellektual'noye upravleniye otsenivaniyem znaniy [Intelligent knowledge assessment management], Maklaut, Cherkassy 2013. - $224 \mathrm{c}$,

4. O. F. Voloshyn, D. I. Kovaliov, "Educational system support to decision making theory", Computer Science And Information, Technologies Conference, Yerevan 2013, 433-434 c.

5. A. Freeman, M. MacDonald, M. Szpuszta, "Pro ASP.NET 4.5 in C\#" [5th Edition] Apress, 2013,

6. H. Kniberg "Scrum and XP from the Trenches (Enterprise Software Development)", www.lulu.com 2007.

7. Voloshyn O. F., Kudin V. I. Vykorystannya novitnikh navchal'nykh tekhnolohiy u Kyyivs'komu natsional'nomu universyteti imeni Tarasa Shevchenka [Use of the latest educational technologies at Taras Shevchenko National University of Kyiv] // Klasychnyy universytet u konteksti vyklykiv epokhy (Classic University in the Context of Challenges of the Epoch) : materialy ukrayins'ko-pol's'koyi mizhnarodnoyi naukovoyi konferentsiyi (m. Kyyiv, 22-23 veresnya 2016 roku) / [uklad.: A. S. Filipenko ta in.]. - K. : Kyyivs'kyy natsional'nyy universytet imeni Tarasa Shevchenka, 2016. -C.16

8. Koval'ov D. I. Servis Dystantsiynoho navchannya u formati sotsial'noyi merezhi [Distance learning service in the format of a social network], Visnyk KNU, Seriya fizyko-matematychni nauky, 2015.

9. Montague, R. English as a formal language / R. Montague, edited by R. H. Thomason // Formal Philosophy. - Yale University Press, 1974.

10. Shvetsov, A.N. Postroyeniye priblizhennoy kontseptual'noy modeli predmetnoy oblasti na osnove analiza smysla yestestvenno-yazykovykh tekstov [Construction of an approximate conceptual model of the subject area based on the analysis of the meaning of natural language texts] / A.N. Shvetsov, V.S. Aleshin // Mezhdunarodnaya konferentsiya po myagkim vychisleniyam i izmereniyam SCM'2003: sb. dokl. T. 2. SPb., 2003. - S. $120-123$. 